\title{
Characterization of Physical and Chemical Properties of Soil from Three Municipal Solid waste Dumpsites in Bayelsa State, Nigeria
}

\author{
Osim, Samuel E. ${ }^{*}$ Etukudo, Mbosowo M.**, Eze, Ukamaka P., ${ }^{* * *}$ Udo, Joseph I. ${ }^{* * * *}$ Akwe, Lucky S. ${ }^{* *}$ \\ *Department of Plant Science and Biotechnology, Cross River State University of Science and Technology. Nigeria \\ ${ }^{* *}$ Department of Biology, Federal University Otuoke, Bayelsa State, Nigeria \\ ****Department of Science Laboratory Technology, Federal Polytechnic, Ekowe, Bayelsa State, Nigeria \\ **** Department of Plant Science and Biotechnology, University of Port Harcourt, Rivers State, Nigeria \\ DOI: 10.29322/IJSRP.10.10.2020.p10655 \\ http://dx.doi.org/10.29322/IJSRP.10.10.2020.p10655
}

\begin{abstract}
Characterization of physical and chemical properties of soil from three municipal solid waste dump sites was conducted in Bayelsa State, Nigeria. Soil samples were collected from three (3) municipal solid waste dumpsites; Opolo (L1), Mechanic village (L2), and Kpansia (L3), along side natural soil (control-PO) in triplicates. Physico-chemical properties and heavy metal contents of the experimental sites were examined. This study revealed that soil $\mathrm{pH}$, total nitrogen, available phosphorus, organic carbon, magnesium, potassium, calcium, and electrical conductivity recorded higher contents $(P<0.05)$ at the dumpsites than the natural soil (control). Exchangeable acidity were lower at the dumpsites than the natural soil, while heavy metals contents were higher at the dumpsites than the natural soil, however, their proportions were within the permissible levels by WHO. Therefore, this study showed that the soil nutrient status and the general soil conditions at the dumpsites were adequate for optimum agricultural productivity.

Index Terms- Physical, Chemical, Soil, Dumpsites, Bayelsa State
\end{abstract}

\section{INTRODUCTION}

Soil is regarded as a medium for plant growth and habitat for a variety of living organisms as well as an important natural resource base for mineral elements needed for plant growth and development ${ }^{1}$. Urbanization, population growth, and socioeconomic development have brought increased accumulation of municipal solid waste together with complexity in management of these wastes ${ }^{2}$. Municipal solid wastes are known to accumulate in tremendous proportion and cause unpleasant sites in some major cities in Nigeria. Further increase in the proportion of municipal solid wastes may be recorded in future due to increased population growth and economic potentials of urban centers ${ }^{3 ; 4 ; 5}$. Soil quality is a crucial factor to be considered for sustainable agriculture, hence, evaluation of soil properties around waste disposal sites becomes increasingly important. The factors influencing the composition of municipal solid wastes at any given time may include culture, affluence, and location ${ }^{6}$. Management of municipal solid wastes has been shown to be dependent on the solid wastes characteristics such as moisture contents, particle size, chemical composition and

This publication is licensed under Creative Commons Attribution CC BY.

http://dx.doi.org/10.29322/IJSRP.10.10.2020.p10655 density ${ }^{6}$, thus, presenting difficulty in solid waste management in terms of economic and technical aspects ${ }^{7}$.

Several open municipal wastes dumpsites are available in Yenagoa, Bayelsa State, and are centrally managed by the State Ministry of Environment. Therefore, this paper presents the evaluation of physical and chemical properties of soils within three (3) selected dumpsites and their comparison with those of the natural soil to assess the impact of pollution potential of open dumping on soil in the urban area of Yenagoa, Bayelsa State, Nigeria

\section{MATERIALS AND METHODS}

Study Area: The study was conducted at three (3) sampling municipal solid waste dumpsite along Opolo, Kpansia, and mechanic village road, Yenagoa, Bayelsa State, Nigeria. These dumpsites are used by the inhabitants for municipal solid waste disposal as Government authorized dumping sites, and usually evacuated by the environmental sanitation authority on regular bases. The research area is in the tropical climatic zone of Nigeria with a mean maximum monthly temperature ranging from $26^{\circ} \mathrm{C}$ to $31^{\circ} \mathrm{C}$. The state is geographically located within latitude $4 \hat{\mathrm{A}}^{\circ} 15^{\prime}$ North and latitude $5 \hat{\mathrm{A}}^{\circ} 23^{\prime}$ South. It is also within longitudes $5 \hat{\mathrm{A}}^{\circ} 22^{\prime}$ West and $6 \hat{\mathrm{A}}^{\circ} 45^{\prime}$ East ${ }^{8 ; 9}$.

\section{Collection of soil samples}

Soil samples were collected $(0-15 \mathrm{~cm}$ depth) from three (3) municipal solid waste dumpsites; Opolo (L1), Mechanic village (L2), and Kpansia (L3), along side natural soil, which served as Control (L0) in triplicates, giving a total of twelve (12) representative samples from both the waste dumpsite and the control soils. The samples were collected using an acid clean soil auger pack in a well labeled black polythene bag and taken to the laboratory for analysis.

\section{Analysis of soil samples}

The soil samples were air-dried at room temperature for two (2) weeks and ground to pass through $2 \mathrm{~mm}$ mesh sieve. The samples were then analyzed for both physical and chemical properties of the soil. Standard methods were used to analyze soil samples for physico-chemical properties ${ }^{10}$. Particle size distribution analysis 
was done by the Hydrometer method ${ }^{11}$. Soil $\mathrm{pH}$ was measured in water at ratio 1:1 (soil: water) by glass electrode $\mathrm{pH}$ meter $\mathbf{1 1}$. Organic matter was determined by wet dichromate acid oxidation method ${ }^{\mathbf{1 2}}$.

The cations were extracted with $1 \mathrm{M}$ ammonium acetate buffered at $\mathrm{pH} 7$ to determine the cation exchange capacity (CEC).. $30 \mathrm{ml}$ of $1 \mathrm{M} \mathrm{CH} 3 \mathrm{COONH} 4$ was added to $5 \mathrm{~g}$ of soil. The suspension was shaken for $2 \mathrm{~h}$ and then centrifuged (15 min, $6000 \mathrm{rpm})$. After centrifugation and filtration, the filtrate was transferred into a $100 \mathrm{ml}$ flask and two other volumes of $30 \mathrm{ml}$ ammonium acetate were added successively after $30 \mathrm{~min}$ of agitation and centrifugation. The final filtrates were completed to $100 \mathrm{ml}$ with ammonium acetate solution

Calcium $(\mathrm{Ca})$ and magnesium $(\mathrm{Mg})$ were determined by EDTA titration while potassium $(\mathrm{K})$ and sodium $(\mathrm{Na})$ were determined by flame photometry. Exchangeable acidity (EA) was determined by titration method ${ }^{13}$. The effective cation exchange capacity (ECEC) was calculated as the total exchangeable bases plus exchangeable acidity.

Available phosphorous (Av. P) was extracted with Bray solution 11 and the phosphorous determined by the molybdenum method described by ${ }^{\mathbf{1 4}}$. The percent organic matter (\%OM) was calculated from the percent organic carbon (OC\%) measured using wet oxidation method ${ }^{15}$. Total nitrogen (TN) was determined using the modified Kjeldahl distillation methods ${ }^{\mathbf{1 3}}$.

\section{Determination of heavy metal contents of soil}

One gram of each of the sieved soil samples was digested using the nitric/perchloric acid digestion procedure ${ }^{\mathbf{1 6}}$. The concentrations of heavy metals, $\mathrm{Pb}, \mathrm{Cr}, \mathrm{Zn}, \mathrm{Fe}, \mathrm{Mn}$ and $\mathrm{Cd}$ were determined using atomic absorption spectrophotometer (Unicam Solaar 32 model) following the standard procedures ${ }^{17}$.

\section{Statistical analysis}

Values of mean data obtained from the replicate readings were used to calculate standard error and data were subjected to analysis of variance (ANOVA).The differences in the means were tested using Least Significant Difference (LSD) at 0.05 level of probability ${ }^{18}$.

\section{RESULTS AND DISCUSSION}

Higher values of $\mathrm{pH}$ were recorded at LI L2 and L3 dumpsites comparable to the control (L0). However, the $\mathrm{pH}$ values of L1 and L3 were slightly alkaline, while that of L2 was slightly acidic. The mean $\mathrm{pH}$ values of soils at dumpsites ranged from 7.43 (L1) to 7.69 (L3), and a relative lower value of 5.32 for L2, while the control (L0) had a $\mathrm{pH}$ value of 5.29 (Table 1). The slightly acidic nature of L2 dumpsite may be due to accumulation of used engine oil, and lubrication oil as well as other wastes usually generated from mechanic villages (vehicle repairs sites). Reduction in soil $\mathrm{pH}$ is one of the adverse impacts of crude oil contamination ${ }^{19}$. Contamination of soil by petroleum oil may also lead to adverse effects such as, adsorption of oil to soil particles, generation of an excess carbon that may be unavailable for microbial use and induction of a limitation in soil nitrogen and phosphorus 20;21. Reduction in $\mathrm{pH}$ may affects nutrient availability in soil, especially increase concentration of aluminium, copper and manganese, while depleting the nitrogen contents of soil ${ }^{22}$. Higher $\mathrm{pH}$ values in dumpsites of municipal solid wastes relative to natural soils have been reported ${ }^{23}$. Elevated $\mathrm{pH}$ at solid waste disposal sites has been attributed to liming materials and microbial activities ${ }^{24 ; 25}$. Similarly, soil under accumulation of municipal solid wastes has been shown to be characterized by increased salinity due to accumulation of organic materials, thus leading to reduction in soil acidity ${ }^{\mathbf{2 6}}$.

The values of exchangeable bases varied significantly among the three sites. Exchangeable calcium, magnesium, and sodium were higher in dumpsites than the control site (Table 1). The higher contents of exchangeable bases at the dumpsites may be attributed to high organic matter contents of soil. High contents of exchangeable bases at a given municipal solid waste dumpsite are usually an indication of high nutrient status together with increased microbial activities ${ }^{27}$. Higher contents of nitrogen and phosphorus were recorded at the three dumpsites (L1, L2 and L3) relative to the control (L0)-(Table 1). Enhanced organic matter content of solid waste dumpsites resulting from higher level of nitrogen and phosphorus has been reported ${ }^{28}$. The values of exchangeable acidity at L1 $(2.31 \mathrm{cmol} / \mathrm{kg}), \mathrm{L} 2(2.40 \mathrm{cmol} / \mathrm{kg})$ and L3 $(2.37 \mathrm{cmol} / \mathrm{kg})$ dumpsites were relatively lower than that of the control $-\mathrm{LO}(2.72 \mathrm{cmol} / \mathrm{kg})$ site (Table 1$)$. This disparity may be due to leaching activities of soil by rain and runoff infiltration, which cause increased acidic ion concentration in soil. Therefore, low acidic ion at the dumpsites may be due to exchangeable bases resulting from decomposing organic waste that replaced the leached cation, hence leading to alkaline nature 29;30

The values of electrical conductivity varied across the three dumpsites (L1, L2 and L3). The values for Electrical conductivity were $0.27,0.32$ and $0.23 \mathrm{ds} / \mathrm{m}$ at L1, L2 and L3 dumpsites, respectively, while that of the control (L0) was 0.07 $\mathrm{ds} / \mathrm{m}$ (Table 1 ). This clearly shows a higher level of electrical conductivity at the dumpsites than the control site. The elevated values of electrical conductivity at the dumpsites may be due to high salt contents usually found in some municipal solid wastes 31;32. Similarly, high value of electrical conductivity at dumpsites has been shown to be attributed to soluble salts often associated with disposal of metallic materials ${ }^{33}$. The soil particle size distribution at the dumpsites as well as the control site indicated a loamy sandy pattern (Table 1), which is a clear characteristic of soil of the Niger Delta region ${ }^{24}$.

There were marked variations in the contents of heavy metal across the three dumpsites as well as the control site (Table 2). Higher contents of heavy metals were recorded at L2 relative to L1 and L3 dumpsites, while the contents of heavy metals at the three dumpsites (L1, L2 and L3) were comparatively lower than that of the control (L0) sites. This variation in heavy metal content at the three dumpsites may be due to the accumulation of residential, municipal and agricultural wastes, which characterized the L1, and L2 dumpsites, while the L2 has additional wastes from vehicle repairs and mechanic shops with their associated heavy metal contents. Heavy metal accumulation 
at waste dumpsites may be absorbed by plants and other soil organisms with their associated adverse effects. Waste dumpsite containing high levels of heavy metals may impose detrimental effects on soil physical and chemical properties, and upset nutrient balance, leading to reduction in plant growth and development ${ }^{34}$. Some metals are known to be harmful and can persist in the soil medium for a long period. It is important to note that some of the soils around the dumpsites are agricultural lands and are under continuous cultivation. The presence of organic matter and nutrients such as phosphorus in the soil can influence the availability of heavy metals for plant uptake, such that high contents of such nutrient can reduce heavy metals contents through processes such as chelation, adsorption and precipitation ${ }^{35}$. Although, the concentration of the heavy metals were within the permissible range, it may however be a threat to human health if ingested above optimum level for safety.

Table 1: Physical and chemical properties of experimental soil

\begin{tabular}{|l|l|l|l|l|}
\hline Sampling sites & $\begin{array}{l}\mathrm{L}_{o} \\
\text { Parameters }\end{array}$ & $\begin{array}{l}\mathrm{L}_{1} \\
\text { Opolo }\end{array}$ & $\begin{array}{l}\mathrm{L}_{2} \\
\text { Mechanic } \\
\text { village }\end{array}$ & $\begin{array}{l}\mathrm{L}_{3} \\
\text { Kpansia }\end{array}$ \\
\hline $\mathrm{pH}$ & $5.29 \pm 0.21$ & $7.43 \pm 0.33$ & $5.32 \pm 0.42$ & $7.67 \pm 0.31$ \\
\hline $\begin{array}{l}\text { Avail. } \mathrm{P} \\
(\mathrm{mg} / \mathrm{kg})\end{array}$ & $6.37 \pm 0.40$ & $10.48 \pm 0.35$ & $8.04 \pm 0.22$ & $12.33 \pm 0.60$ \\
\hline Total N $(\%)$ & $0.24 \pm 0.02$ & $3.14 \pm 0.10$ & $2.62 \pm 0.20$ & $3.67 \pm 0.23$ \\
\hline TOC $(\%)$ & $1.30 \pm 0.80$ & $3.67 \pm 0.21$ & $5.08 \pm 0.34$ & $4.02 \pm 0.28$ \\
\hline $\mathrm{EC}(\mathrm{ds} / \mathrm{m})$ & $0.07 \pm 0.01$ & $0.27 \pm 0.03$ & $0.32 \pm 0.02$ & $0.23 \pm 0.04$ \\
\hline $\mathrm{Na}(\mathrm{Cmol} / \mathrm{kg})$ & $0.12 \pm 0.02$ & $0.20 \pm 0.03$ & $0.18 \pm 0.02$ & $0.15 \pm 0.03$ \\
\hline $\mathrm{Mg}(\mathrm{Cmol} / \mathrm{kg})$ & $1.74 \pm 0.30$ & $3.06 \pm 0.25$ & $3.54 \pm 0.42$ & $2.83 \pm 0.26$ \\
\hline $\mathrm{K}(\mathrm{Cmol} / \mathrm{kg})$ & $0.16 \pm 0.05$ & $0.24 \pm 0.02$ & $0.20 \pm 0.04$ & $0.25 \pm 0.02$ \\
\hline $\mathrm{Ca}(\mathrm{Cmol} / \mathrm{kg})$ & $3.06 \pm 0.27$ & $7.13 \pm 0.39$ & $6.58 \pm 0.17$ & $5.24 \pm 0.61$ \\
\hline EA $(\mathrm{Cmol} / \mathrm{kg})$ & $2.72 \pm 0.32$ & $2.31 \pm 0.18$ & $2.40 \pm 0.80$ & $2.37 \pm 0.22$ \\
\hline $\begin{array}{l}\text { ECEC } \\
(\mathrm{Cmol} / \mathrm{kg})\end{array}$ & $6.90 \pm 0.20$ & $8.82 \pm 0.26$ & $9.33 \pm 0.52$ & $9.08 \pm 0.39$ \\
\hline Sand $(\%)$ & $76.40 \pm 0.44$ & $73.04 \pm 0.57$ & $80.21 \pm 0.37$ & $72.70 \pm 0.46$ \\
\hline Silt $(\%)$ & $5.87 \pm 0.31$ & $12.73 \pm 0.20$ & $11.60 \pm 0.23$ & $11.21 \pm 0.72$ \\
\hline Clay $(\%)$ & $17.73 \pm 0.22$ & $14.23 \pm 0.69$ & $8.19 \pm 0.40$ & $16.09 \pm 0.13$ \\
\hline
\end{tabular}

Mean \pm standard error of 3 replicates

Table 2: Heavy metal contents of experimental soil

\begin{tabular}{|l|l|l|l|l|}
\hline Sampling sites & $\begin{array}{l}\mathrm{L}_{0} \\
\text { Parameters } \\
\text { Cong/kg }\end{array}$ & $\begin{array}{l}\mathrm{L}_{1} \\
\text { Opolo }\end{array}$ & $\begin{array}{l}\mathrm{L}_{2} \\
\text { Mechanic } \\
\text { village }\end{array}$ & $\begin{array}{l}\mathrm{L}_{3} \\
\text { Kpansia }\end{array}$ \\
\hline Zinc & $0.13 \pm 0.03$ & $0.16 \pm 0.02$ & $0.56 \pm 0.05$ & $0.27 \pm 0.02$ \\
\hline Chromium & $0.04 \pm 0.02$ & $0.08 \pm 0.02$ & $0.98 \pm 0.04$ & $0.07 \pm 0.01$ \\
\hline Nickel & $0.01 \pm 0.01$ & $0.20 \pm 0.05$ & $0.86 \pm 0.07$ & $0.10 \pm 0.03$ \\
\hline Cadmium & $0.27 \pm 0.05$ & $0.40 \pm 0.02$ & $0.74 \pm 0.05$ & $0.31 \pm 0.04$ \\
\hline Lead & $0.21 \pm 0.03$ & $0.34 \pm 0.02$ & $0.82 \pm 0.03$ & $0.25 \pm 0.04$ \\
\hline Iron & $0.10 \pm 0.04$ & $0.45 \pm 0.03$ & $0.77 \pm 0.05$ & $0.24 \pm 0.03$ \\
\hline Copper & $0.02 \pm 0.01$ & $0.15 \pm 0.05$ & $0.37 \pm 0.03$ & $0.18 \pm 0.02$ \\
\hline Manganese & $0.22 \pm 0.05$ & $0.27 \pm 0.02$ & $0.45 \pm 0.02$ & $0.25 \pm 0.03$ \\
\hline
\end{tabular}

Mean \pm standard error of 3 replicates

\section{CONCLUSION}

This study showed that soil characteristics such as soil $\mathrm{pH}$, total nitrogen, available phosphorus, organic carbon, magnesium, potassium, calcium, and electrical conductivity recorded higher contents at the dumpsites than the natural soil (control). The contents of exchangeable acidity at the dumpsites were lower than that of the natural soil. In addition, the contents of heavy metals at the dumpsites were higher than that of the natural soil, however, their proportions were within the permissible levels by WHO. Therefore, this study clearly revealed that the soil nutrient levels as well as the general soil conditions at the dumpsites were adequate for optimum growth and development of plants.

\section{AKNOWLEDGEMENT}

We remain grateful to Mr. Lucky Segun Akwe for painstakingly collecting the research samples, sorting and assembling them for analysis.

\section{REFERENCES}

[1] R. N. Uma, R. Prem Sudha, D. K. Murali. Analysis of physico chemical characteristics of soil around municipal solid waste Dump yard In Vellalore- Coimbatoretamilnadu, India. Int. J. Chem. Sci., 14(4), 2016, 3265- 3276.

[2] T. Karak, R. M. Bhagat, P. Bhattacharyya, "Municipal solid waste generation, composition and management: the world scenario," Critical Reviews in Environmental Science and Technology, 42(5), 2012, 1509-1630.

[3] Central Pollution Control Board (CPCB). Status of municipal solid waste generation, collection, treatment and disposal in class 1 cities CPCB, New Delhi, India, 2000.

[4] S. Sharma, K.W. Shah. Generation and disposal of solid waste in Hoshangabad Proceedings of the 2nd International Congress of Chemistry and Environment. Indore, India. 2005, 749-751.

[5] T. Hazra, S. Goel. Solid waste management in Kolkata, India: practices and challenges. Waste Management, 29 (1), 2009, 470-478

[6] C. Eneje, C. Roseta. T. Lemoha Kelechi. Heavy metal content and physicochemical properties of municipal solid waste dump soils in Owerri, Imo State. International Journal of Modern Engineering Research (IJMER), 2(5), 2012, 3795-3799.

[7] J. Pastor, A. J. Hernández. Heavy metals, salts and organic residues in old solid urban waste landfills and surface waters in their discharge areas: determinants for restoring their impact. 95, 2012, S42-S49.

[8] Niger Delta Source: Bayelsa State. http://nigeriadeltasource.com/bayelsa, 2014.

[9] Bayelsa New Media Team News: Bayelsa State General Information Area. www.bayelsa.gov.ng/ www.bayelsanewmediateam.com, 2012.

[10] IITA.Selected methods for soil and plant analysis. IITA (International Institute of Tropical Agriculture). Manual Series No. 1, Ibadan, 1979.

[11] E.O. McLean. Methods of soil analysis, Part 2: Chemical and biological properties, Black, C.A. (Ed.). American Society of Agronomy, Madison, WI., USA., 1965, pp. 987- 990.

[12] D.W. Nelson, L.E. Sommers, Total carbon, organic carbon and organic matter: In: A.L. Page, R.H. Miller and D.R. Keeney) Methods of soil analysis. Part 2 Chemical and microbiological properties, 1982 , pp. $539-579$ 
[13] A.S.R. Juo, Selected methods for soil and plant analysis. International Institute of Tropical Agriculture (IITA), Ibadan, Nigeria, 1979.

[14] E. J. Udo, J.A. Ogunwale. Laboratory manual for the analysis of soils, plant and water samples. 1st Edn., Department of Agronomy, University of Ibadan, Nigeria, 1978,pp. 45.

[15] A. Walkley, I.A. Black, An examination of the degtjarett method of determining soil organic matter and proposed modification of the chromic acid titration method soil. Soil Soc., 37, 1934, 29-38.

[16] C.T.I. Odu, O. Babalola, E.J. Udo, A.O. Ogunkule, T. A. Bakere G.O. Adeoye . Laboratory Manual for Agronomic studies in soil, plant and microbiology. University of Ibadan, Ibadan Press Ltd., 1986, pp. 83.

[17] APHA. Standard methods for the examination of water and wastewater, 16th edition. American Public Health Association, Washington DC., 1985.

[18] I. U. Obi. Statistical Methods of Detecting Differences Between Treatment Means and Research Methodology Issues in Laboratory and Field Experiments. Nigeria: AP Express Publishers Limited; 2002.

[19] M .M. Etukudo, I. E. Okon, S.E. Osim, A. Egbe, P. Eremrena. Tolerance of Abelmoschus esculentus to diesel oil polluted soil. Global Journal of Environmental Science, 10(1\&2), 2011, 5-9.

[20] U. George- Okafor, F. Tasie, F. Mustoe- Okafor. Hydrocarbon degradation potentials of indigenous fungal isolates from petroleum contaminated soils. Journal of Physical and Natural Sciences. 3(1), 2009,1-6.

[21] J. C. Okolo, E. N. Amadi, C.T. I. Odu, Effects of soil treatment containing poultry manure on crude oil degradation in a loamysandy soil. Applied Ecology and Environmental Research, 3(1), 2005, 41-53.

[22] M. N. Tijani, S. O. Onibalusi, A. S. Olatunji. Hydochemical and environmental impact assessment of Orita Aperin waste dumpsite,Ibadan, southwestern Nigeria. Water Resources 13, 2002, 78.

[23] F.U. Obianefo, I. O. Agbagwa, F.B.G. Tanee. Physicochemical characteristics of soil from selected solid waste dump sites in Port Harcourt, Rivers State, Nigeria J. Appl. Sci. Environ. Manage . 21 (6), 2017, 1153-1156.

[24] B. B. Ayade. Indigenous biological treatment of hydrocarbon contaminated soil in the tropics. Journal of Nigerian Environmental Society, 1(1), 2003, 87-94.

[25] T.J.K. Ideriah, V.O.T. Omuaru, P.U. Adiukwu. Soil quality around asolid waste dumpsite in Port Harcourt. African Journal of Ecology, 44(3), 2006, 388-394.

[26] N. O. Isirimah. Soil and Environmental Pollution Management, Nichadano Publishers, Owerri, Nigeria, 2000, pp.14.

[27] C. I. Okonkwo, P. Arinzechukwu, C. Njoku. Changes in physical and chemical properties of soil in timber sawmill dumpsite in Abakaliki, Abakaliki Southeastern, Nigeria, Int. J. Environ. Climate Change, 1 (2013), pp. 215-228
[28] T.J.K. Ideriah, F.O. Harry, H.O. Stanley, J.K. Igbara. Heavy metal contamination of soils and vegetation around solid waste dumps in Port Harcourt, Nigeria. Journal of Applied science Envrionmental Mangement, 14(1), 2010, 101-109.

[29] O. E. Essien, R. O. Hanson. Municipal solid waste dumpsite pollution on physico-chemical properties of dumpsite and surrounding soils. International Journal of Engineering Research \& Technology (IJERT),2(4), 2013

[30] E. Edem. Soil pollution and its management in Enugu urban, Enugu State", Seminar on Tropical Environment, Enugu State University of Technology, Enugu, 2007.

[31] Food and Agricultural Organisation (FAO), Land and plant nutrient services. Global Network on Integrated Soil Management for Sustainable use of salt affected soils". FAO of Rome, 2000.

[32] J. D. Rhoades, F. Chanduvi, S. Lesch, S. Soil Salinity Assessment - Methods and Interpretation of electrical Conductivity Measurement". Irrigation and Drainage Paper No. 57, FAO of UN, Rome, 1999.

[33] N.A. Obasi, E.I. Akubugwo, O.C. Ugbogu, G. Otuchristian Assessment of physico-chemical properties and heavy metals bioavailability in dumpsites along Enugu-port Harcourt Expressways, South-east, Nigeria, Asian J. Appl. Sci., 5,2012, 342-356.

[34] FAO/ITPS Status of the world's soil resources (SWSR)-main report Food and agriculture organization of the United Nations and intergovernmental technical panel on soils, Rome, Italy, 2015. p. 650

[35] A. Chahab, G. Savaghebi. Effect of zinc application on cadmium uptake and maize growth Agricult. Segment, 1(1), 2010,AGS/1515

\section{Authors}

First Author -Dr. Samuel E. Osim, Senior Lecturer, Cross River State University of Science and Technology. Nigeria.

Second Author - Dr. Mbosowo M. Etukudo, Associate Professor of Plant Physiology, Federal University Otuoke, Bayelsa State, Nigeria.

Third Author - Ukamaka P. Eze, B.Sc., Federal Polytechnic, Ekowe, Bayelsa State, Nigeria

Fourth Author - Joseph I. Udo, B.Sc., M.Sc., University of Port Harcourt, Rivers State, Nigeria.

Fifth Author -Lucky S. Akwe, Research Student, Federal University Otuoke, Bayelsa State, Nigeria.

Correspondence Author - Dr. Mbosowo M. Etukudo, mbosombosowo@yahoo.com, mbosombosowo@gmail.com +2347032448796 . 